\title{
Spontaneous mechanical aortic valve leaflet dislocation during implantation
}

\author{
Emmanouel Papadakis ${ }^{1}$, Thomas Martens ${ }^{2}$, and Meletios Kanakis ${ }^{3}$ \\ ${ }^{1}$ Onassis Cardiac Suegery center \\ ${ }^{2}$ University Hospital Ghent Heart Center \\ ${ }^{3}$ Affiliation not available
}

December 26, 2020

\begin{abstract}
Acute or delayed mechanical valve fracture with possible migration is a rare problem seen after valve replacement. We report a patient where mechanical aortic valve leaflet detachment was encountered during implantation. The missing leaflet was retrieved in the left atrium at the level of the right lower pulmonary vein. This has not yet been described, and prompt recognition and intervention is warranted.

\section{Spontaneous mechanical aortic valve leaflet dislocation during implantation}

Papadakis Emmanouel ${ }^{1}$, Martens Thomas ${ }^{2}$, Kanakis Meletios ${ }^{3}$

$13^{\text {rd }}$ Department of Cardiac Surgery, Onassis Cardiac Surgery Center, Athens, Greece

2 Department of Cardiac Surgery, Ghent University Hospital, Ghent, Belgium

3 Department of Pediatric and Congenital Heart Surgery, Onassis Cardiac Surgery Center, Athens, Greece

Corresponding author

Thomas Martens

Thom.martens@ugent.be

Phone: +3293320538
\end{abstract}

Key words:

Aortic valve, valve replacement, mechanical valve, adult cardiac surgery

\section{ORCID ID:}

Emmanuel PAPADAGAKIS: https://orcid.org/0000-0002-6994-9148

Thomas MARTENS: https://orcid.org/0000-0002-3736-362

Meletios KANAKIS: https://orcid.org/0000-0002-9708-0523

\section{Abstract}

Acute or delayed mechanical valve fracture with possible migration is a rare problem seen after valve replacement. We report a patient where mechanical aortic valve leaflet detachment was encountered during 
implantation. The missing leaflet was retrieved in the left atrium at the level of the right lower pulmonary vein. This has not yet been described, and prompt recognition and intervention is warranted.

\section{Case description}

A 68-year-old patient having severe aortic valve stenosis was scheduled for valve replacement. Intraoperatively, a $19 \mathrm{~mm}$ St. Jude Regent (St. Jude Medical, Minneapolis, MN, USA) mechanical valve was implanted. During inspection of the valve, one of the leaflets detached from the pivoting system towards the left ventricle (Figure 1B).

Exploration through the aortic valve was ineffective. Through an incision at the Sondergaard's groove, the migrated disc was found at the orifice of the right inferior pulmonary vein.

The prosthesis was detached and a new $19 \mathrm{~mm}$ mechanical valve was implanted. The patient had an uneventful postoperative course. Strangely, meticulous inspection of the explanted prosthesis and leaflet did not reveal fracture of the strut or pivoting system. (Fig 1A).

Spontaneous leaflet missing or fracture of mechanical valve prosthesis is uncommon in literature [1]. In most reports, a fracture of the leaflet is seen after extraction [2-4]. Overall, outcomes of mechanical aortic valve replacement is excellent [5]. Although extremely rare, the possibility of leaflet detachment should be taken into account and prompt action is mandatory.

\section{Figures}

\section{Figure 1}

Panel A:

Explanted mechanical valve with retrieved leaflet.

Panel B:

Surgeon's view with the mechanical valve in place, lacking one leaflet (white asterisk).

\section{Data availability statement}

Data available on request from the authors.

\section{Funding}

None.

\section{Conflict of interest}

None.

\section{References}

1. van Steenbergen GGJ, Tsang QHY, van der Heide SM, Verkroost MWA, Li WWL, Morshuis WJ. Spontaneous leaflet fracture resulting in embolization from mechanical valve prostheses. Journal of cardiac surgery. 2019;34(3):124-30.

2. Fragoulis S, Palatianos GM. Fractured prosthetic valve leaflet. European journal of cardio-thoracic surgery : official journal of the European Association for Cardio-thoracic Surgery. 2008;34(4):907.

3. Mosterd A, Shahin GM, van Boven WJ, Jaarsma W, Graafland AD, van Swieten HA. Images in cardiovascular medicine. Leaflet fracture of a St. Jude mechanical bileaflet valve. Circulation. 2005;111(18):e280-1.

4. Raut MS, Maheshwari A, Dubey S. Missing leaflet of prosthetic aortic valve. Journal of cardiothoracic and vascular anesthesia. 2015;29(2):e20-1. doi: 10.1053/j.jvca.2014.10.011. 
5. Minakata K, Tanaka S, Okawa Y, Kaneko T, Okonogi S, Usui A, et al. Twenty-year outcome of aortic valve replacement with St. Jude Medical mechanical valves in Japanese patients. Circulation journal : official journal of the Japanese Circulation Society. 2015;79(11):2380-8.

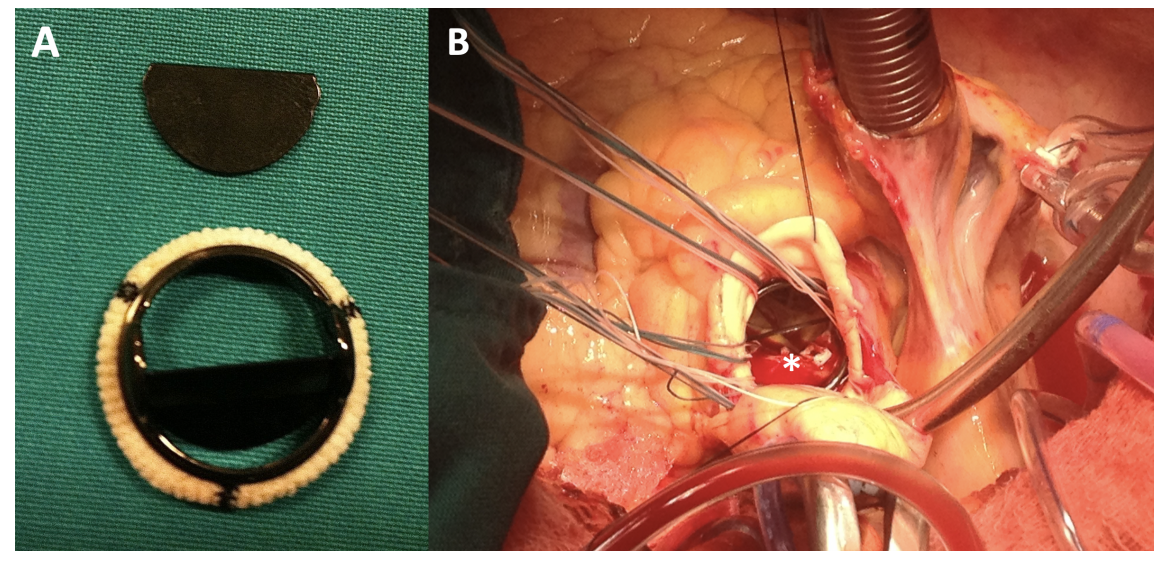

